\title{
Deposition of amyloid in the gastrointestinal tract
}

\author{
T. GILAT, M. REVACH, AND E. SOHAR \\ From the Gastrointestinal Unit, Ichilov Hospital, Tel-Aviv, \\ and the Department of Clinical Research, Tel-Hashomer Hospital, \\ Tel-Aviv University Medical School, Israel
}

Amyloid may cause widespread damage to the gastrointestinal tract. Affection of blood vessels may lead to infarction and perforation of the bowel (Brody, Wertlake, and Laster, 1964; Akbarian and Fenton, 1964) as well as to bleeding or loss of protein into the lumen of the gut (Jarnum, 1965); damage to the musculature or nervous elements may cause marked alterations in motility (Gilat and Spiro, to be published); and mucosal destruction may lead to impaired absorption (Beddow and Tilden, 1960). The presence of amyloid in a tissue does not evoke an inflammatory response and damage is apparently caused by local replacement of tissue. Knowledge of the anatomo-histological site of amyloid deposition may, therefore, help in understanding and anticipating the clinical manifestations. Perusal of reported cases of amyloidosis with gastrointestinal manifestations failed to reveal any pattern or trend: the deposition of amyloid appeared to be quite haphazard and unpredictable. The present study was, therefore, initiated to study systematically the site of amyloid deposition in the digestive tract in a large number of cases.

Amyloid is an extracellular scleroprotein with a characteristic fibrillar structure as seen by electron microscopy (Cohen and Calkins, 1959; Gafni, Merker, Shibolet, Sohar, and Heller, 1966). The weight of recent evidence favours the thesis of local production (Cchen, Gross, and Shirahama, 1965; Gafni et al, 1966) apparently by reticuloendothelial cells (Cohen, 1967). The detection and localization of amyloid in histological sections has been much facilitated by the use of polarized light. When Congo red-stained sections are viewed with the polarizing microscope amyloid exhibits a typical green birefringence which allows of the detection of even minute amounts of amyloid as well as its exact localization in various histological structures (Ravid, Gafni, Sohar, and Missmahl, 1967).

\section{MATERIALS AND METHODS}

Postmortem material from 70 cases of amyloidosis was examined, and the 68 cases in which the gastrointestinal tract was found to be affected form the material of this study (Table I). Two cases (one multiple myeloma, one

\section{TABLE I}

CASE MATERIAL

\begin{tabular}{lr} 
Disease & $\begin{array}{r}\text { No. of } \\
\text { Cases }\end{array}$ \\
\hline Familial Mediterranean fever & 31 \\
Acquired (secondary) amyloidosis & 21 \\
(Hodgkin's disease 4, tuberculosis 4, bronchiectasis 3, & \\
leprosy 3, rheumatoid arthritis 3, chronic pyelonephritis 1, \\
hypernephroma 1, regional enteritis 1, ulcerative colitis 1) \\
$\begin{array}{l}\text { Primary amyloidosis } \\
\text { Multiple myeloma }\end{array}$ \\
Total & 14 \\
& 68
\end{tabular}

regional enteritis) form part of a previous study (Gilat and Spiro, 1968). The rest of the case material was collected from various medical centres in Israel, with most of it coming from the Tel-Hashomer Hospital where the genetic type of familial Mediterranean fever amyloidosis has been extensively studied (Sohar, Gafni, Pras, and Heller, 1967). Formalin-fixed, paraffin-embedded, Congo-red-stained sections $7 \mu$ thick were examined by light microscopy using ordinary and polarized light.

On examination attention was directed to the presence, amount, and distribution of amyloid in mucosa, muscularis mucosae, blood vessels, submucosa, muscularis, serosa, and myenteric plexus. The submucosal plexus could not be reliably identified on Congo-redstained sections. Amyloid deposition was graded as obvious or minimal, with the former including moderate to massive deposits. In some sections changes due to autolysis were present to a varying degree. This, however, did not interfere with the localization of amyloid, especially when polarized light was used.

\section{RESULTS}

Amyloid was found in submucosa and serosa only in and around the walls of blood vessels. These two structures have, therefore, been omitted from the tables and graph. In all cases of this series amyloid was found in blood vessels. Amyloid was detected in blood vessels in all layers of the bowel wall but was most apparent in the submucosa, probably because 
of the large number of blood vessels in this layer. In each case amyloid was deposited in blood vessels exclusively in one of two ways: in the 'inner layer', including intima and media, or in the 'outer layer', including adventitia and media. This was most obvious in arterioles due to the relative thickness of media and least apparent in venules due to thinness of media. Slightly larger arterioles and venules were usually involved in the 'outer layer' type of deposition. Amyloid was found in capillaries only in the 'inner layer' type of deposition. The two types of vascular involvement are illustrated in Figures 1 and 2.

In the cases where portions of all or most organs of the gastrointestinal tract were available, it was apparent that with some variations amyloid deposition in each case was qualitatıvely similar in all organs. For example, if amyloid was found in the mucosa and blood vessels of the stomach, it was usually found in the same structures of the oesophagus and small and large bowel, although in some of them it might be present in blood vessels only. If it was in the inner layer of blood vessels in one organ, it was found in the same layer in all other organs. If muscularis and blood vessels were involved in one part of the digestive tract, blood vessels with or without muscularis were involved in all other parts. In no case did we find only mucosal involvement in one part of the gastrointestinal tract with only muscular involvement in another part.

In the group of cases of familial Mediterranean fever, amyloid was deposited in the inner layer of blood vessels in all cases and in the mucosa in the majority of these. There was no amyloid deposited in the muscularis but the muscularis mucosae was involved in some cases (Tables II and III). Amyloid was deposited in the mucosa more frequently in the small bowel than in the stomach and colon. When

TABLE II

AMYLOID DEPOSITION IN THE DIGESTIVE TRACT IN 68 CASES $^{1}$

Disease

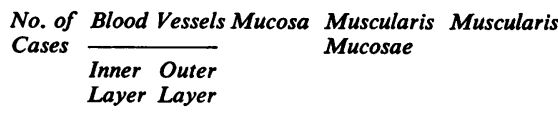

Familial

Mediterranean

$\begin{array}{lll} & 31 & 31\end{array}$

amyloidosis

Primary

amyloidosis

Multiple

myeloma

2

$21 \quad 21$

\begin{tabular}{|ccc} 
& $16(4)^{2}$ & $8(6)$ \\
& $14(3)$ & $7(3)$ \\
$13(1)$ & $3(2)$ & $9(4)$ \\
& &
\end{tabular}

${ }^{1}$ If amyloid was found in a layer in any part of the digestive tract the layer is considered affected in this table.

'Numbers in parentheses represent cases with minimal deposition of amyloid. Numbers without parentheses represent cases with obvious deposition of amyloid.

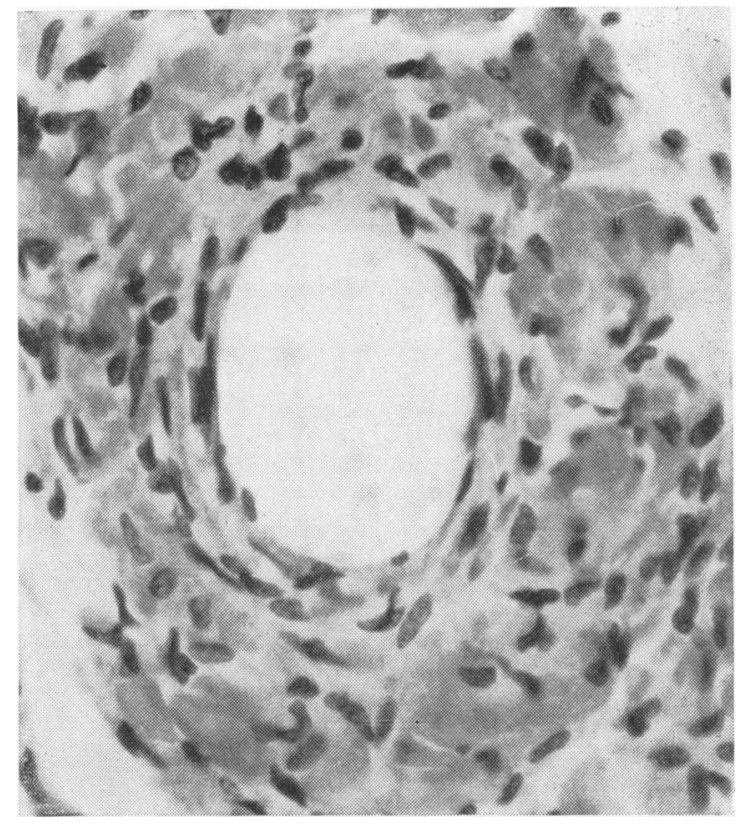

FIG. 1a. Arteriole in pericollagen amyloidosis. Amyloid is seen in the adventitia and media; the intima is unaffected. The vessel appears to be encased in a mass of amyloid. Congo red $\times 460$.

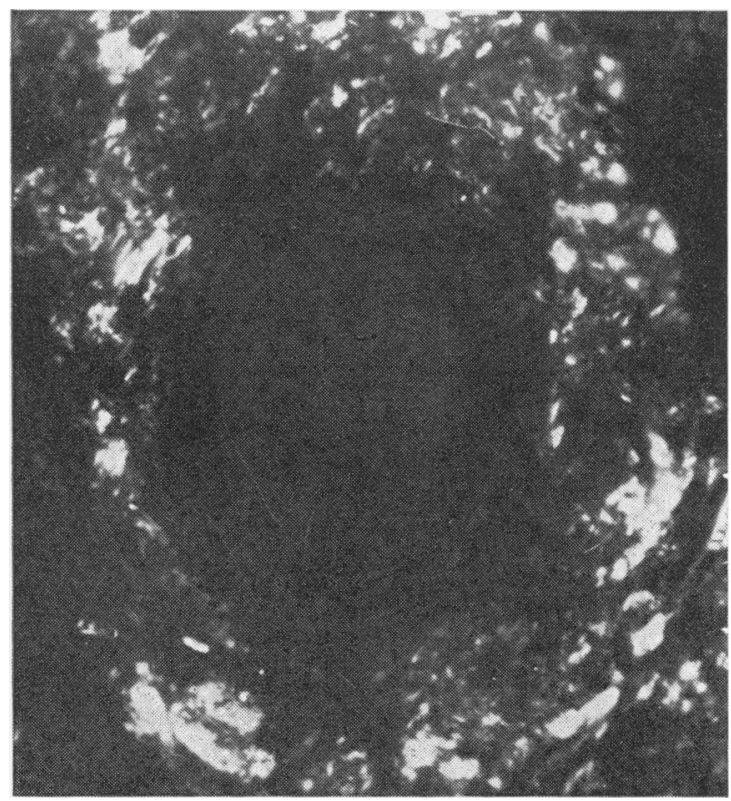

FIG. 1B. Same as Fig. Ia viewed with polarized light. Light spots represent birefringent amyloid. The central part of the vessel is free of amyloid. 


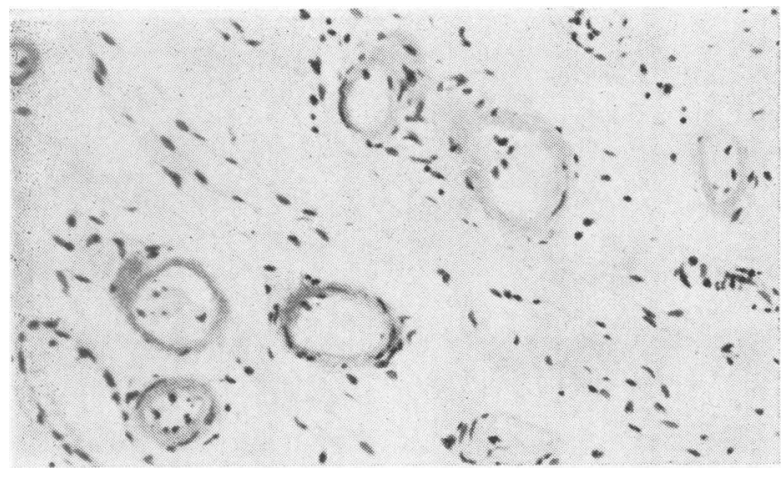

FIG. 2a. Arterioles in perireticulin amyloidosis. These small arterioles consist mostly of intima and media and the whole wall appears waxy and involved with amyloid. Due to lack of amyloid in and around adventitia the walls appear much less thickened and they are not surrounded by a mass of amyloid as is seen in Figure 1. Congo red $\times 80$.

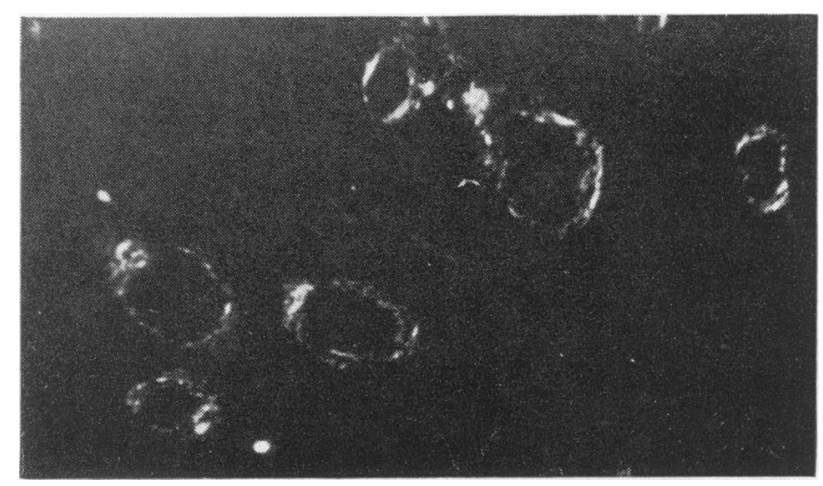

FIG. 2b. Same section as in Fig. 2a viewed with polarized light.

the mucosa was involved in all three organs, deposits of amyloid were usually more massive in the small bowel. Amyloid deposited in the mucosa was mostly in the region of the epithelial and glandular basement membrane, within the connective tissue framework of the lamina propria, and in association with capillaries (Figs. 3 and 4). Mucosal architecture was usually unaffected even in some cases with massive deposits. In 'secondary' amyloidosis amyloid deposition was very similar to that described in the familial Mediterranean fever group. The only difference was a moderate amount of amyloid deposited in the muscularis in two out of 21 cases and minimally in three (Tables II and III). In all these cases amyloid was present in much larger amounts in the mucosa.

In the group with 'primary' amyloidosis amyloid was present in blood vessels in all cases always in the outer layer of the vessels. Parenchymal deposition of amyloid was mainly in the muscular layers. The muscularis mucosae was almost always involved and the muscularis was involved in more than half the cases, often quite massively. In some cases amyloid was found in the mucosa, but in all of these cases it was present to a much more marked degree in the muscularis. In cases with minimal and moderate involvement of muscular layers amyloid was seen between and in close apposition to muscle fibres. In massive deposits there were degenerative changes in muscle fibres, muscle tissue being replaced by amyloid. In some cases with heavy involvement most of the muscle layer was replaced by amyloid in numerous places (Fig. 5).

In the two cases with multiple myeloma the distribution of amyloid in the blood vessels and the various layers of the bowel wall was almost identical to that described for primary amyloidosis. Therefore, these two groups are listed together in Table III. Material from the oesophagus was available in only nine cases and is not presented in tabular form. In general, in each case the distribution of amyloid in the various layers of the oesophageal wall followed the pattern found in the other gastrointestinal organs.

Amyloid was found in the myenteric plexus in one case of primary amyloidosis. In two cases of secondary amyloidosis with muscular involvement small amounts of amyloid were found in the vicinity of the myenteric plexus. It could not be determined whether the plexus was actually involved.

\section{TABLE III}

AMYLOID DEPOSITION IN GASTROINTESTINAL ORGANS

$\begin{array}{lll}\text { Disease } & \text { No. of Blood Vessels } \\ \text { Cases } & \frac{\text { Mucosa }}{\text { Inner Outer }} & \begin{array}{l}\text { Muscularis Muscularis } \\ \text { Mucosae }\end{array}\end{array}$

\section{Stomach}

Familial

Mediterranean

Secondary

amyloidosis

Primary

amyloidosis and

multiple

myeloma

Small Bowel

6

$6 \quad 2(1)$

$2(3)^{1} \quad 3(3)$

1(2)

1(1)

$\begin{array}{rrrrrr}23 & 23 & - & 12(5) & 5(4) & - \\ 15 & 15 & - & 9(2) & 5(1) & 1(1) \\ 14 & - & 12(2) & 1(1) & 6(5) & 8(1)\end{array}$

Colon

$\begin{array}{rrrrrr}21 & 21 & - & 3(2) & 1(1) & - \\ 11 & 11 & - & 6(3) & 2(4) & (3) \\ 7 & - & 6(1) & (1) & 1(1) & 6\end{array}$

${ }^{1}$ Numbers in parentheses represent cases with minimal deposition of amyloid. Numbers without parentheses represent cases with obvious deposition of amyloid. 


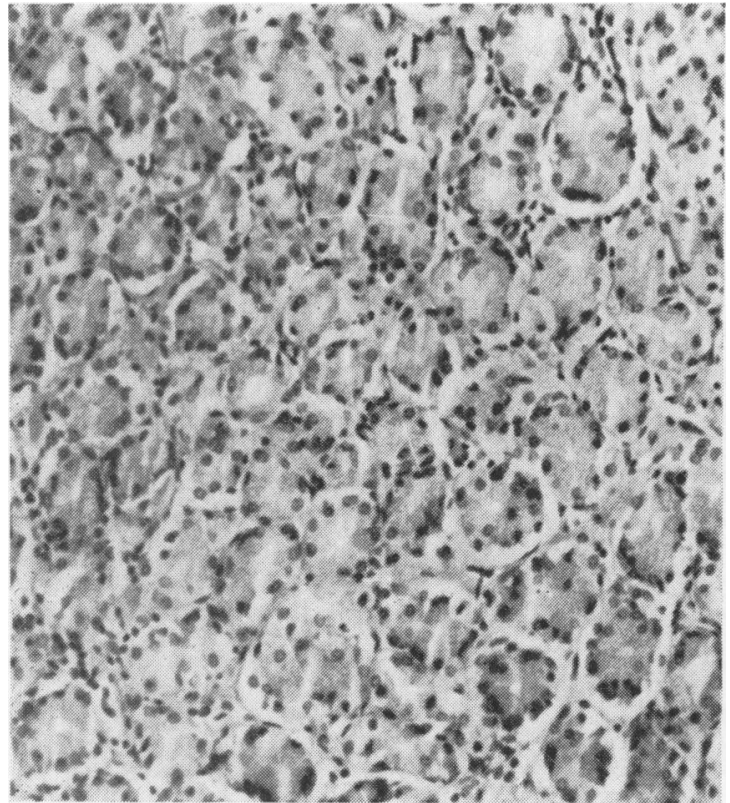

FIG. 3.

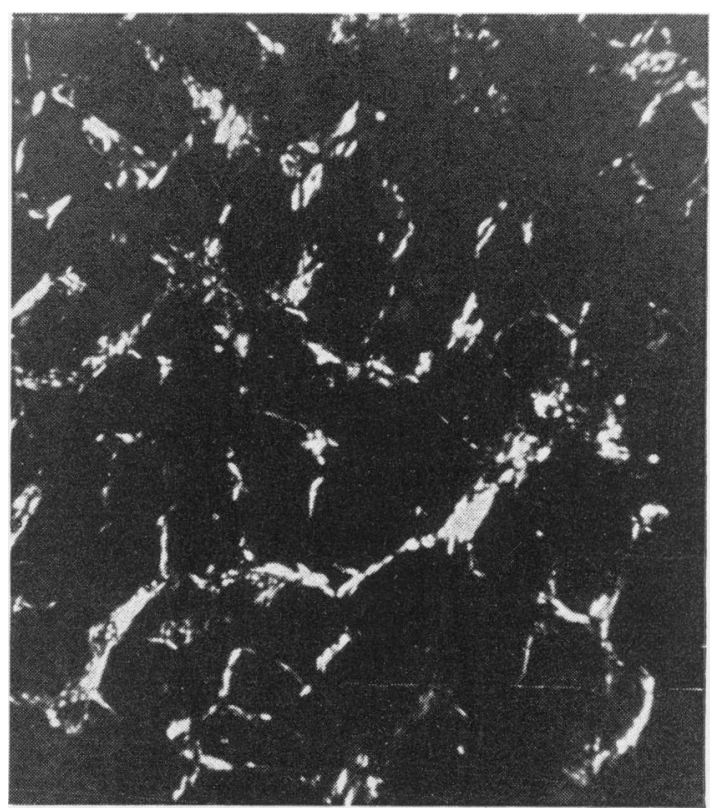

FIG. 4.

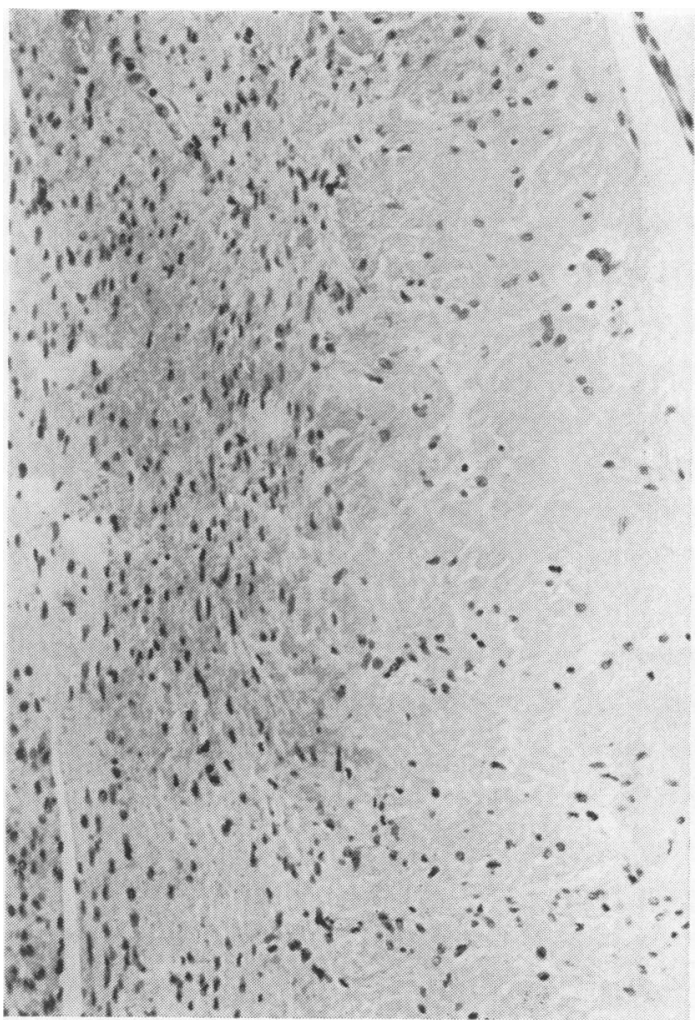

FIG. 3. Gastric mucosa (gastric gland area) in perireticulin (familial Mediterranean fever) amyloidosis. Note normal mucosal architecture. The presence of amyloid is not readily apparent. Congo red $\times 120$.

FIG. 4. Same mucosa viewed with polarized light. Moderate amounts of amyloid are apparent.

FIG. 5. Muscularis in pericollagen (primary) amyloidosis. Amyloid replacing portions of muscle in upper part of figure. Note waxy appearance with paucity of nuclei. Congo red $\times 100$.

FIG. 5 . 


\section{DISCUSSION}

Our data show two distinct modes of amyloid deposition in the gut wall. In amyloidosis associated with familial Mediterranean fever and in secondary amyloidosis (group 1) amyloid is always deposited in the inner coat of small blood vessels. In primary amyloidosis and amyloidosis associated with multiple myeloma (group 2) amyloid is deposited in the outer coat of small and medium sized blood vessels. There was no case of overlap in the type of vascular involvement between the two groups (Fig. 6). Parenchymal deposition of amyloid in group 1 was mainly in the mucosa, while in group 2 it was mainly in the muscularis. In no case of group 1 was amyloid present only in the muscularis and in no case of group 2 was it present only in the mucosa. In a few cases with massive amyloid deposits in the mucosa in group 1 there was some amyloid in the muscularis and in a few cases with massive involvement of the muscularis in group 2 there was some amyloid in the mucosa. In both gioups the muscularis mucosae was involved, much more so in group 2.

Previous classifications of amyloidosis based on
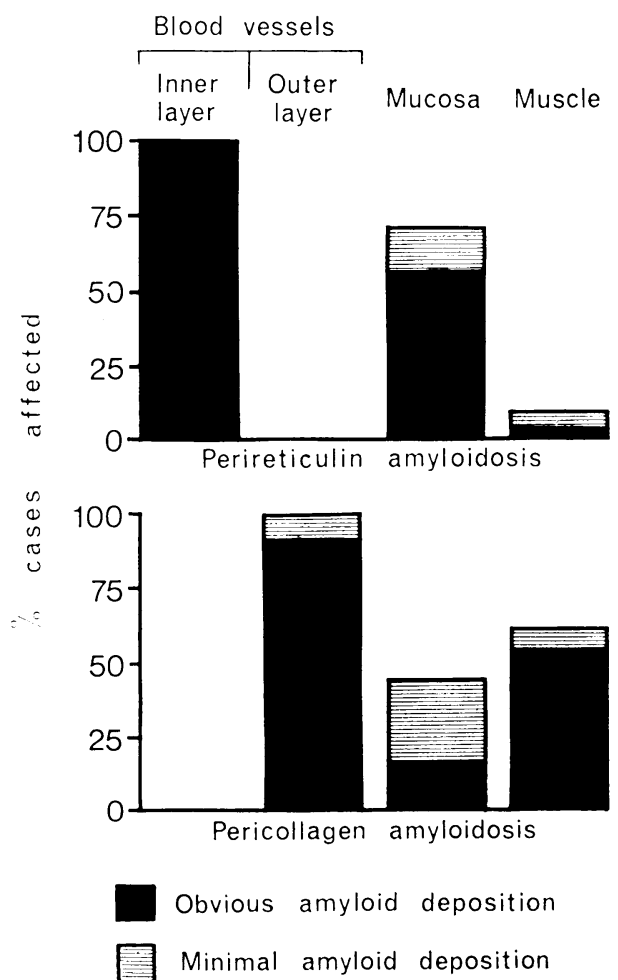

FIG. 6. Amyloid deposited in the gut wall. organ involvement and staining characteristics of amyloid were unsatisfactory and with marked overlap between the groups. Heller, Missmahl, Sohar, and Gafni (1964) divided all cases of amyloidosis into two groups, pericollagen and perireticulin, based mainly upon the mode of small vessel involvement on histological examination. Essentially, in perireticulin amyloidosis initial amyloid deposits are subintimal while in pericollagen amyloidosis they are adventitial (Sohar, Merker, Missmahl, Gafni, and Heller, 1967). These are the respective sites of the maximal concentration of reticulin and collagen fibres in the vessel. In each type the distribution of amyloid outside blood vessels is also along reticulin or collagen fibres. It soon became apparent that with very few exceptions all cases of amyloidosis of the same disease entity belong to the same histological type. Perireticulin amyloidosis was found mainly in the hereditary form associated with familial Mediterranean fever and in the acquired form of the secondary amyloidoses. Pericollagen amyloidosis was found mainly in the hereditary and idiopathic forms of classical primary amyloidosis (neuropathic or cardiopathic) and in the acquired form associated with multiple myeloma.

It is evident that our group 1 corresponds to perireticulin amyloidosis and group 2 to pericollagen amyloidosis according to blood vessel involvement. The diagnoses in our cases also fit this classification. Involvement of muscular structures in one group and basement membrane structures in the mucosa in the other group is also in agreement with the described parenchymal deposition of amyloid in this classification. Our material does not include some of the rarer types of amyloidosis.

Most large series of cases of amyloidosis reported in the literature fail to give precise figures for incidence and quantitative data on layer and organ involvement in the digestive tract (Bero, 1957; Hallen and Rudin, 1966). Some authors who give more precise data describe findings which are in agreement with our own. Symmers (1956), reviewing primary amyloidosis, states that amyloid in the stomach and intestines is laid down in and around blood vessels and between muscle fibres. Dahlin (1949), in 15 cases of secondary amyloidosis involving the gastrointestinal tract, found only blood vessels affected in six, whereas blood vessels and mucosa were involved in the other nine cases. In 'some' there were small deposits in the muscularis mucosae and muscularis.

The case reports of patients with amyloidosis presenting with gastrointestinal symptoms are not very numerous and give the impression that amyloid deposition is very variable and haphazard. This reflects lack of adequate criteria for classification. 
Review of the literature in English yielded 37 cases of amyloidosis involving the gastrointestinal tract in which an adequate microscopic description of amyloid deposited in the various layers was given. Only cases with a postmortem examination and one case with surgical material were included. Cases with suction biopsies were not included as these do not contain all layers of the bowel wall. The mode of vascular involvement could not be determined from these reports. We have, therefore, arranged the cases according to the clinical diagnoses into pericollagen and perireticulin types. Twelve cases were thus presumed to be of the perireticulin type (Adlesberg and Schein, 1947; Jensen, Bargen, and Baggenstoss, 1950; Bassett, Adams, Goldman, and Fishkin, 1952; Golden, 1954; Mandelbaum and Bryk, 1955; Beddow and Tilden, 1960; Gelderman, Levine, and Arndt, 1962; Targgart, Trump, Lagunoff, and Eschbach, 1963; Shibolet and Gafni, 1964; Benedek and Zawadzki, 1966). In all of these 12 cases amyloid was found in blood vessels and in 10 in the mucosa also. In only one of them (Targgart et al, 1963) was amyloid found in the muscularis of the stomach, although not in that of the oesophagus or small bowel. Blood vessels and mucosa were involved in all three organs.

Twenty-five cases were presumed to be of the pericollagen type (Randall, 1933; Pearson, Rice, and Dickens, 1941; Golden, 1945; Findley and Adams, 1948; Andrade, 1952; Clausen, cited by Cooley, 1953; Cooley, 1953; Lubarsch, cited by Cooley, 1953; Steinhaus, cited by Cooley, 1953; Golden, 1954; Perloff, 1954; Shnider and Burka, 1955; Intriere and Brown, 1956; Korelitz and Spindell, 1956; Heitzman, Heitzman, and Elliott, 1962; Liske, Chou, and Thompson, 1963; Akbarian and Fenton, 1964; Brody et al, 1964; Massachusetts General Hospital Case Records, 1964; Casad and Bocian, 1965; French, Hall, Parish, and Smith, 1965; Long, Mahony, and Jewell, 1965). Blood vessels were involved in all these 25 cases and the muscularis in 22. There were only small deposits of amyloid in the mucosa in four cases, in all of which the muscularis was involved. In two cases the myenteric plexus was involved.

These facts are in surprisingly good agreement with our own and show that grouping cases of amyloidosis according to the histological site of deposition permits a meaningful classification.

In our study gastrointestinal tract involvement was found in 68 of 70 cases of systemic amyloidosis. This is a much higher proportion than usually reported in the literature and is due probably to a systematic search and better detection with the use of polarized light. It follows that in almost all cases of systemic amyloidosis the diagnosis can be made by biopsy of the digestive tract, provided that the biopsy is deep enough to include the submucosa (Green, Higgins, Brown, Hoffman, and Sommerville, 1961; Blum and Sohar, 1962; Cohen and Loery, 1963; Kyle, Spencer, and Dahlin, 1966).

Based upon the results of our own study and supported by the reported review of the literature, we may anticipate the histological type of digestive tract involvement in the various entities of amyloidosis. The type of amyloidosis can be anticipated according to the disease and ascertained by histological study of vascular involvement. Knowledge of the anatomical and histological sites of amyloid deposition may help in anticipating and understanding the clinical manifestations. Thus, impaired motility may be more frequent in pericollagen amyloidosis due to muscular damage, and malabsorption might be expected in some cases of perireticulin amyloidosis with massive involvement of the mucosa.

\section{SUMMARY}

The histological distribution of amyloid in the various organs of the gastrointestinal tract was studied in 68 cases of systemic amyloidosis involving the bowel. Two patterns of amyloid deposition were found. In all cases amyloid was present in blood vessels, mainly in the submucosa. In the secondary amyloidoses and amyloidosis associated with familial Mediterranean fever, amyloid was deposited in the inner coat of small blood vessels, while parenchymal deposition of amyloid was predominantly in the mucosa. In primary amyloidosis and amyloidosis associated with multiple myeloma, amyloid was found in the outer coat of small and medium sized blood vessels while parenchymal deposition was predominantly in the muscle layers. These two patterns correspond to the recent classification of amyloidosis into perireticulin and pericollagen types respectively. The literature was reviewed and most reported cases were found to conform to these same patterns.

We wish to thank Dr Howard Spiro of Yale University for helpful advice and criticism throughout the study as well as for his review of the manuscript. The study was supported in part by USPHS grants nos. 6X5126 and Am-09272.

\section{REFERENCES}

Adlesberg, D., and Schein, J. (1947). Clinical and pathologic studies in sprue. J. Amer. med. Ass., 134, 1459-1467.

Akbarian, M., and Fenton, J. (1964). Perforation of small bowel in amyloidosis. Arch. intern. Med., 114, 815-821.

Andrade, C. (1952). A peculiar form of peripheral neuropathy. Familiar atypical generalized amyloidosis with specific involvement of the peripheral nerves. Brain, 75, 408-427. 
Bassett, S. H., Adams, W. S., Goldman, R., and Fishkin, B. G. (1952). Nontropical sprue complicated by generalized amyloidosis. Med. Clin. N. Amer., 36, 1173-1185.

Beddow, R. M., and Tilden, I. L. (1960). Malabsorption syndrome due to amyloidosis of the intestine secondary to lepromatous leprosy; a report of a case. Ann. intern. Med., 53, 1017-1027.

Benedek, T. G., and Zawadzki, Z. A. (1966). Ankylosing spondylitis with ulcerative colitis and amyloidosis. Amer. J. Med., 40, 431-439.

Bero, G. L. (1957). Amyloidosis: its clinical and pathologic manifestations, with a report of 12 cases. Ann. intern. Med., 46, 931-955.

Blum, A., and Sohar, E. (1962). The diagnosis of amyloidosis: ancillary procedures. Lancet, 1, 721-724.

Brody, I. A., Wertlake, P. T., and Laster, L. (1964). Causes of intestinal symptoms in primary amyloidosis. Arch. intern. Med., 113, $512-518$.

Casad, D. E., and Bocian, J. J. (1965). Primary systemic amyloidosis simulating acute idiopathic ulcerative colitis: report of a case. Amer. J. dig. Dis., 10, 63-74.

Clausen, A. (1935). Cited by Cooley. Fall von röntgenologisch wahrnehmbarer Magenamyloidose. Fortsch. Geb. Röntgenstr. 51, 528-532.

Cohen, A. S. (1967). Amyloidosis. New Engl. J. Med., 277, 522-530.

, and Calkins,.E. (1959). Electron microscopic observations on a fibrous component in amyloid of diverse origins. Nature (Lond.), 183, 1202-1203.

- - Gross, E., and Shirahama, T. (1965). The light and electron microscopic autoradiographic demonstration of local amyloid formation in spleen explants. Amer. J. Path., 47, 1079-1111.

Cohen, T., and Loery, W. H. (1963). Peroral mucosal biopsy in the diagnosis of gastrointestinal amyloidosis. Amer. J. Gastroent., 39, 165-172.

Cooley, R. N. (1953). Primary amyloidosis with involvement of the stomach. Amer. J. Roentgenol., 70, 428-436.

Dahlin, D. C. (1949). Secondary amyloidosis. Ann. intern. Med., 31, 105-119.

Findley, J. W., Jr, and Adams, W. (1948). Primary systemic amyloidosis simulating constrictive pericarditis. Arch. intern. Med., 81, 342-351.

French, J. M., Hall, G., Parish, D. J., and Smith, W. T. (1965). Peripheral and autonomic nerve involvement in primary amyloidosis associated with uncontrollable diarrhoea and steatorrhea. Amer. J. Med., 39, 277-284.

Gafni, J., Merker, H. J., Shibolet, S., Sohar, E., and Heller, H. (1956). On the origin of amyloid. Study of an amyloid tumor in multiple myeloma. Ann. intern. Med., 65, 1031-1044.

Gelderman, A. H., Levine, R. A., and Arndt, K. A. (1962). Dermatomyositis complicated by generalized amyloidosis. New Engl. J. Med., 267, 858-861.

Gilat, T., and Spiro, H. (1968). Amyloidosis and the gut. Amer. J. dig. Dis., 13, 619-633.

Golden, A. (1945). Primary systemic amyloidosis of the alimentary tract. Arch. intern. Med., 75, 413-416.

Golden, R. (1954). Amyloidosis of the small intestine. Amer. J. Roentgenol., 72, $401-408$.

Green, P. A., Higgins, J. A., Brown, A. K., Jr, Hoffman, H. N., II, and Somerville, R. L. (1961). Amyloidosis: appraisal of intubation biopsy of the small intestine in diagnosis. Gastroentero$\log y, 41,452-456$.

Hallen, J., and Rudin, R. (1966). Peri-collagenous amyloidosis. A study of 51 cases. Acta med. scand., 179, 483-499.
Heitzman, E. J., Heitzman, G. C., and Elliott, C. F. (1962). Primary esophageal amyloidosis. Arch. intern. Med., 109, 595-600.

Heller, H., Missmahl, H. P., Sohar, E., and Gafni, J. (1964). Amyloidosis: its differentiation into peri-reticulin and peri-collagen types. J. Path. Bact., 88, 15-34.

Intriere, A. D., and Brown, C. H. (1956). Primary amyloidosis. Report of a case of gastric involvement only. Gastroenterology, 30, 833-838.

Jarnum, S. (1965). Gastrointestinal haemorrhage and protein loss in primary amyloidosis. Gut, 6, 14-18.

Jensen, E. J., Bargen, J. A., and Baggenstoss, A. H. (1950). Amyloidosis associated with chronic ulcerative colitis. Gastroenterology, 15, 75-83.

Korelitz, B. I., and Spindell, L. N. (1956). Gastrointestinal amyloidosis. J. Mt Sinai Hosp., 23, 683-696.

Kyle, R. A., Spencer, R. J., and Dahlin, D. C. (1966). Value of rectal biopsy in the diagnosis of primary systemic amyloidosis. Amer. J. med. Sci., 251, 501-506.

Liske, E., Chou, S. M., and Thompson, H. G., Jr (1963). Peripheral and autonomic neuropathy in amyloidosis. A case report. J. Amer. med. Ass., 186, 432-434.

Long, L., Mahoney, T. D., and Jewell, W. R. (1965). Selective amyloidosis of the jejunum. Case report of a rare cause for gastrointestinal bleeding. Amer. J. Surg., 109, 217-220.

Lubarsch, O. (1929). Cited by Cooley. Zur Kenntnis ungewöhnlichen Amyloidablagerungen. Virchows Arch. path. Anat., 271, 867-889.

Mandelbaum, I., and Bryk, D. (1955). Idiopathic chronic ulcerative colitis and amyloidosis. J. Mt Sinai Hosp., 22, 24-33.

Massachusetts General Hospital Case records. Case 13-1964. (1964). New Engl. J. Med., 270, 574-582.

Pearson, B., Rice, M. M., and Dickens, K. L. (1941). Primary systemic amyloidosis: report of 2 cases in negroes, with special reference to certain histologic criteria for diagnosis. Arch. Path., 32, 1-10.

Perloff, J. K. (1954). Some unusual cutaneous, cardiac and gastrointestinal manifestations of systematized amyloidosis associated with multiple myeloma. J. Mt Sinai Hosp., 21, 195-208.

Randall, O. S. (1933). Multiple myeloma complicated by intestinal obstruction due to amyloid infiltration of the small intestine. Amer. J. Cancer, 19, 838-846.

Ravid, M., Gafni, J., Sohar, E., and Missmahl, H. P. (1967). Incidence and origin of non-systemic microdeposits of amyloid. J. clin. Path., 20, 15-20.

Shibolet, S., and Gafni, J. (1964). Fatal malabsorption syndrome in F.M.F. amyloidosis. Proc. Tel-Hashomer Hosp., 3, 117-118.

Shnider, B. I., and Burka, P. (1955). Amyloid disease of the stomach simulating gastric carcinoma. Gastroenterology, 28, 424-430.

Sohar, E., Gafni, J., Pras, M., and Heller, H. (1967). Familial Mediterranean fever. A survey of $\mathbf{4 7 0}$ cases and review of the literature. Amer. J. Med., 43, 227-253.

- Merker, H. J., Missmahl, H. P., Gafni, J., and Heller, H. (1967). Electron-microscope observations on peri-reticulin and pericollagen amyloidosis in rectal biopsies. J. Path. Bact., 94, 89-93.

Symmers, W. St. C. (1956). Primary amyloidosis: a review. J. clin. Path., 9, 187-211.

Steinhaus, F. (1902). Ueber eine seltene Form von Amyloid-und Hyalin-Infiltration um Circulations-und Digestionsapparat. Z. klin. Med., 45, 375-384.

Targgart, W. H., Trump, B. F., Lagunoff, D., and Eschbach, J. (1963) Systemic amyloidosis and ulcerative colitis. Gastroenterology, 44, 335-341. 